\title{
Performance assessment of fused deposition modeling process
}

\author{
Abdulrahman Al-Ahmari*, Syed Hammad Mian** and Wadea Ameen***,**** \\ *Industrial Engineering Department, College of Engineering, King Saud University, Riyadh 11421, Saudi Arabia \\ **Advanced Manufacturing Institute, King Saud University, Riyadh 11421, Saudi Arabia \\ ***Industrial Engineering Department, College of Engineering and Architecture, Al Yamamah University, Riyadh 11512, Saudi Arabia \\ ****Corresponding Author: w_qaid@yu.edu.sa
}

Submitted: 01/10/2019

Revised: $\quad 13 / 08 / 2020$

Accepted: $27 / 08 / 2020$

\begin{abstract}
Fused deposition modeling (FDM) is an additive manufacturing method that offers numerous benefits in terms of simplicity, ease of operation, material strength, flexibility, etc. However, its fabricated parts have frequently been affected by poor dimensional and geometrical accuracy. It is, therefore, extremely crucial to examine the numerous causes of errors in FDM so that appropriate steps can be taken to address its limitations. In this work, an attempt has been made to quantify the various sources of errors that contribute to the poor accuracy of FDM fabricated parts. For this reason, a standard part (also referred to as benchmark part), which is comprised of various shapes, features, and geometries, was used for the evaluation of the FDM process. The predominant goal of this research was to characterize the FDM process in terms of dimensions and geometrical accuracy. Although this research was specific to a particular machine, it provided useful information regarding the procedure that can be employed whenever a benchmark part will be utilized. This work can also act as a foundation to further improvement to the FDM machine design and expansion of its applications.
\end{abstract}

Keywords: additive manufacturing (AM), fused deposition modeling (FDM), coordinate measuring machine (CMM), benchmarking, accuracy.

\section{INTRODUCTION}

Fused deposition modeling (FDM) has been among the most pursued techniques in additive manufacturing (AM). That is because it is user-friendly, is easy-to-use, and can deliver intricate forms. FDM creates components in additive fashion by the sequential accumulation of layers of materials. Basically, it utilizes a plastic wire that passes through the extrusion head into an extrusion nozzle. The extrusion head is provided with both the supporting material and the building component material as depicted in Figure 1. The extrusion head is heated to melt the wire materials, while the software controls its mobility. The material cools down from the nozzle after extrusion and builds a layer. When a layer is generated, the building platform lowers, and the extrusion nozzle places another layer. This cycle of appending layers continues until the user achieves the desired three-dimensional (3D) object. 


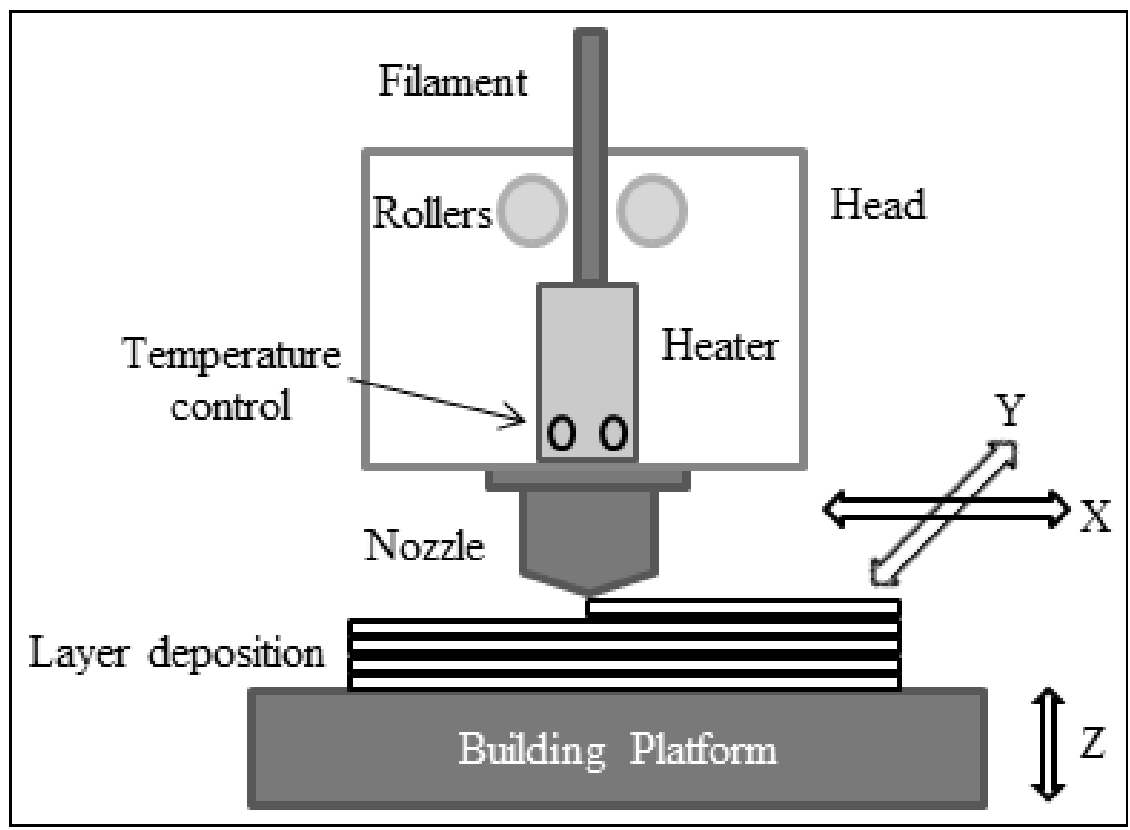

Figure 1. Schematic of fused deposition modeling (Ahn et al., 2009).

The FDM method commences with the import of the model's Standard Tessellation Language (STL) file into the processing program (Kochan et al., 1999). The imported model is then positioned and cut into different layers of thickness to generate the tool trajectory. Finally, the tool path is passed to the FDM unit for the fabrication of models. The part and the desired support are built through subsequent movements of the extrusion head ( $\mathrm{x}$ - and $\mathrm{y}$-directions) and the building platform (z-direction). There are several variables, such as dimensional accuracy, warpage, repeatability, surface quality, building speed, and cost that describe the effectiveness of the FDM system. To envision the accuracy of the FDM process, Sood et al. determined the influence of layer thickness, part location, raster angle, air gap, and raster width on the dimensional quality (Sood et al., 2009). Consequently, Ciurana et al. utilized the design of experiment (DOE) strategy to study the influence of deposition angle, slenderness, filaments distance, etc., on the porosity and the mechanical properties of the scaffolds created by a 3D printer machine known as RepRap (Ciurana et al., 2013), whereas Singh et al. examined the impact of component placement on the dimensional accuracy and mechanical characteristics of the Selective Laser Sintering (SLS) process (Singh et al., 2012). The evaluation of expensive manufacturing systems using a benchmark part has been a prominent approach (Lee et al., 2004). This is because the setup of costly production systems, rapid prototyping (RP) machines, or advancements in the existing practices, etc. involves huge capital investments. Benchmarking has been an important tool for analyzing the output characteristics of the AM processes or any manufacturing method in that respect. A benchmark can be outlined as the baseline for assessing the effectiveness as well as the efficacy of any production system (Fahad et al., 2012). Benchmarking has been a remarkable tool for evaluating system capabilities with regard to its advantages and limitations. For instance, Lee et al. developed a benchmark model for the evaluation of the FDM process in manufacturing the sacrificial investment casting (IC) patterns. Several benchmark parts for the performance analysis of AM systems can be cited in the previous research (Lee et al., 2004). The part designed by Fahad et al. (Fahad et al., 2012) can be used to test the consistency of any process. They divided the part's base into three regions, where each region is comprised of features at the same spot. It also included a variety of features, namely, flat base, cube, hollow cylinder, solid cylinder, sphere, cone, etc. Correspondingly, Mahesh et al. developed a benchmark component and carried out a research to evaluate the performance of RP machines. This benchmark part consisted of many features, like the square frame, cube, flat beam, cylindrical holes, cones, slots, brackets, etc. (Mahesh et al., 2004). Kruth et al. 
also developed a benchmark model to analyze the advantages as well as the drawbacks of various SLS/Selective Laser Melting (SLM) methods. They verified the precision, material characteristics, mechanical aspects, efficiency, and reliability of these systems (Kruth et al., 2004). The part designed by Castillo was employed to explore the attributes of multiple additive technologies for the production of challenging features (Castillo, 2005).

The benchmark part adopted by Moylan et al. can also be used to understand the various sources of errors in the FDM (Moylan et al., 2014). The literature includes many studies related to AM benchmarking, but they were not systematic and are thus challenging to enact. It is crucial for the FDM users, to understand beforehand the machine's applications. Therefore, depending on the application, the user can either select the existing standard part or design the new part. Moylan et al. have focused on the usage of standard parts as they can save a great deal of time, energy, and expense. The methodology adopted by Moylan et al. can be utilized to assess the machine's performance in any given environment, and it can be employed to confirm the manufacturer's specifications. Furthermore, any system can be tested using the proposed methodology for any given set of factors and environmental variables. Henceforth, in the current work, the authors have used the benchmark part developed by Moylan et al. to measure, and thereby estimate, the errors existing in the FDM process.

\section{METHODOLOGY}

FDM system and Dimension Elite 3D printer (Courtesy: Stratasys) have been assessed for the geometrical accuracy, repeatability, and surface quality. The suggested framework has been defined in Figure 2. This approach was initiated with the selection of the standard part. The relevant steps of this methodology can be outlined as follows.

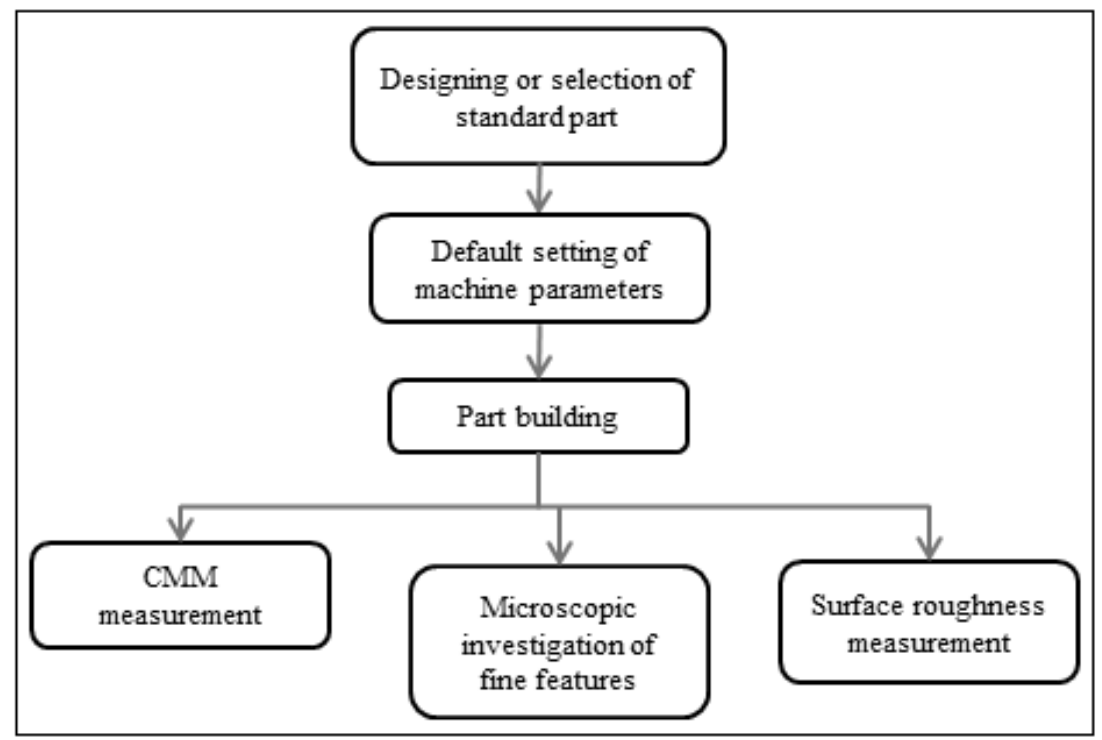

Figure 2. Methodology adopted to investigate the FDM machine.

\section{SELECTION OF TEST PART}

A benchmark test part, shown in Figure 3, was selected from the literature (Moylan et al., 2014) to evaluate the given FDM machine. This design of the benchmark part consisted of a variety of commonly available geometric shapes and sizes. According to Richter et al. (1992) and Scaravetti et al. (2008), the part selected for the assessment of any device should be easy to measure; that is, it should incorporate numerous small, medium, and large geometric shapes as well as features, such as holes, bosses, flat surfaces, and thin walls. Besides, the test part should not demand large volumes of material and perhaps posttreatment. It should also provide measurements for repeatability. 


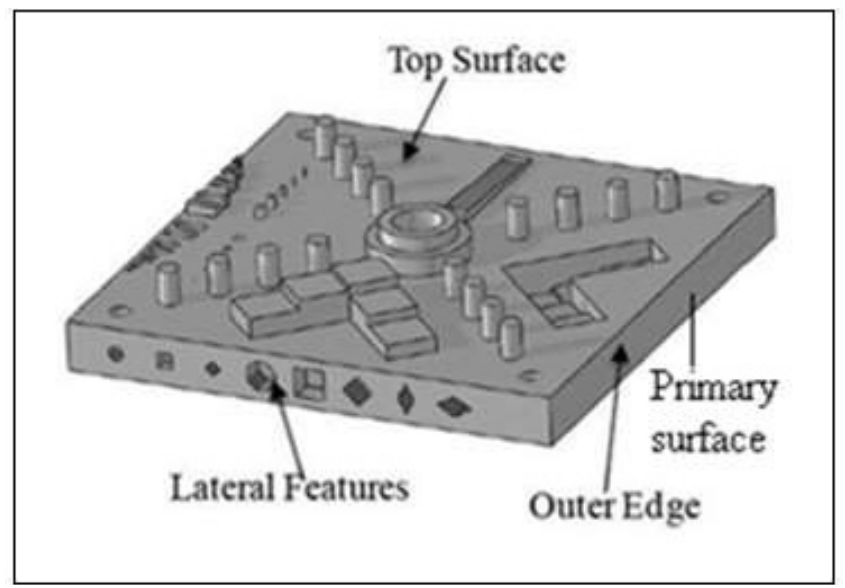

Figure 3. Benchmark part used in this study (Moylan et al., 2014).

The selected benchmark part in this study not only consisted of all the desired characteristics, but it also allowed the measurement of repeatability by including the features in a symmetrical manner.

\section{FDM MACHINE}

Dimension Elite 3D printer (Courtesy: Stratasys), as can be seen in Fig. 4 (a), was assessed to ascertain its ability for generating various geometrical features. This process, based on the FDM principle, used Acrylonitrile Butadiene Styrene (ABS) as a material for part production. This machine can manufacture components with dimensions up to $203 \times 203 \times 305 \mathrm{~mm}$ and layer thicknesses ranging from $0.178 \mathrm{~mm}$ to $0.254 \mathrm{~mm}$.

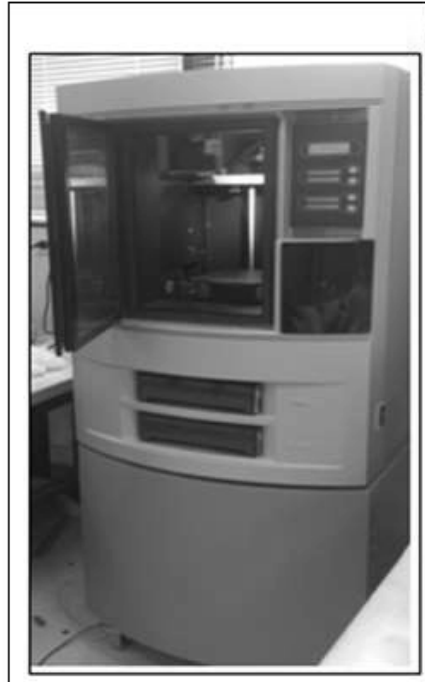

(a)

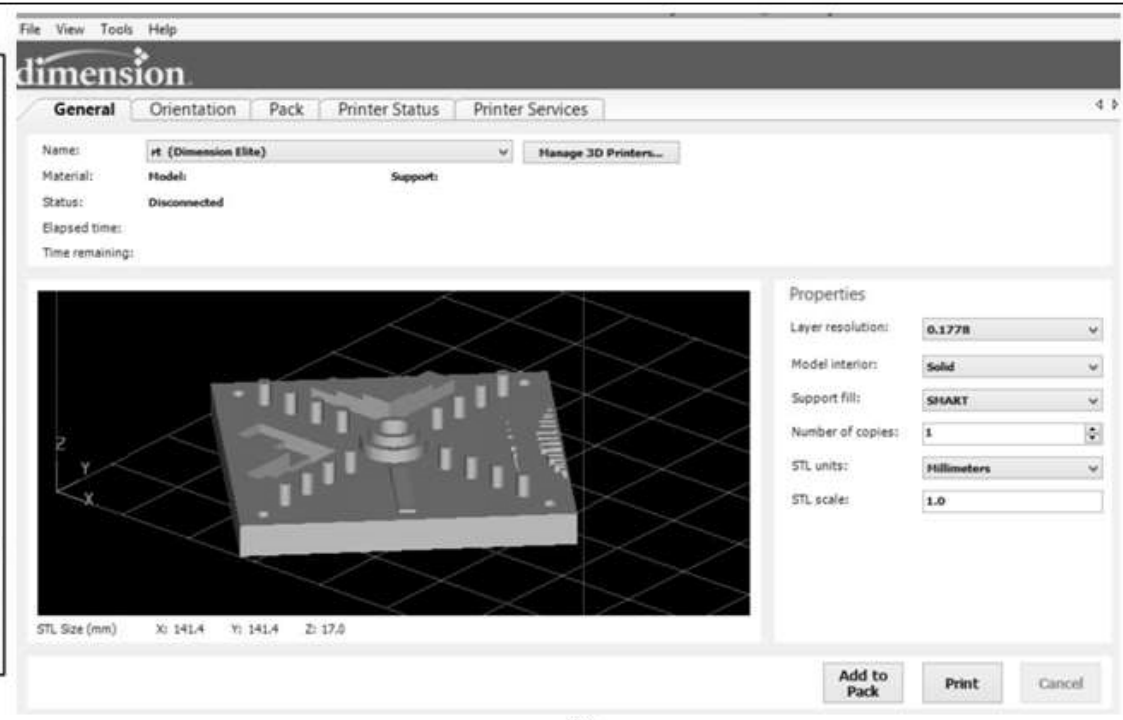

(b)

Figure 4. (a) Dimension Elite 3D Printer (Courtesy: Stratasys). (b) Part orientation and building parameters.

To select the appropriate building parameters for the machine, preliminary studies, as well as prior experience with the machine, were used. The different parameters selected for the manufacturing of a given test part, as well as its orientation in the workspace, can be seen in Fig. 4 (b). Since this part was not very large, it was decided to keep 
the model interior as solid. The solid interior resulted in the robust part, which helped in the precise fixturing and the accurate measurement using the Coordinate Measuring Machine (CMM). In the case of support, a smart option was selected because it helped in the selection of the most appropriate and optimal support for the given part. However, the layer resolution was kept at $0.1778 \mathrm{~mm}$ (minimum for the machine), which provided better results in terms of the accuracy albeit with longer building time. It has also been mentioned by Abu Bakar et al. (2010) that the thinner layers produce a smoother surface finish. The part fabricated by the FDM process using the given set of parameters can be viewed in Figure 5.

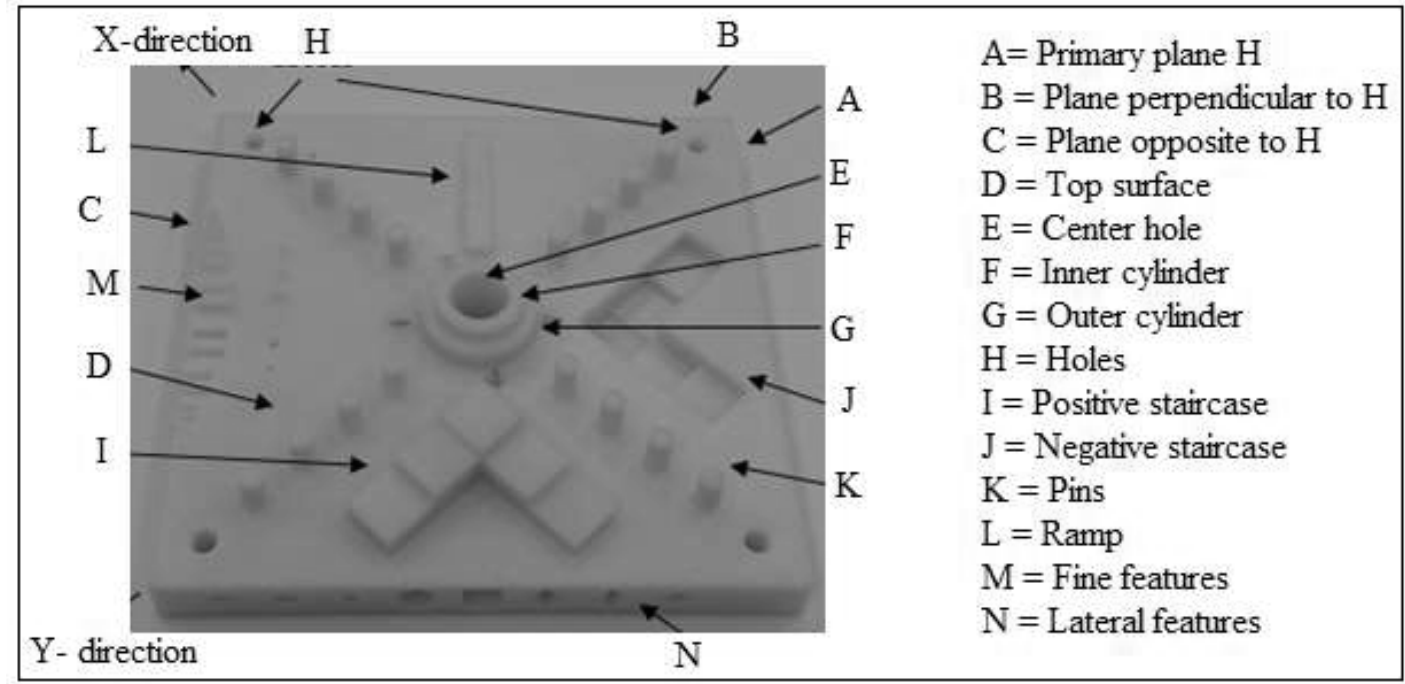

Figure 5. Benchmark part as produced using the FDM process.

\section{MEASUREMENT PROCEDURE}

The measurement program used to measure the different features was written on a computer-controlled CMM. The Bridge type CMM (Courtesy: Zeiss), equipped with a touch-trigger probe, which was employed to conduct the measurements in this investigation, can be seen in Figure 6. All the features and accompanying dimensions of the part were measured three times, and accordingly their averages were estimated.

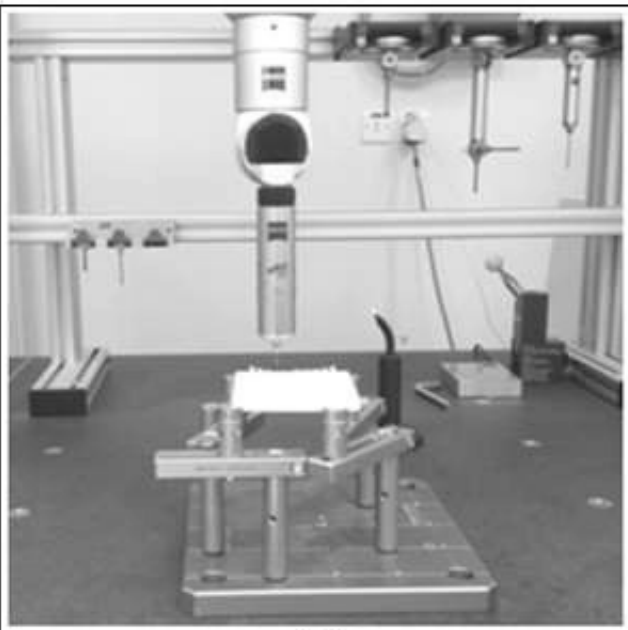

(a)

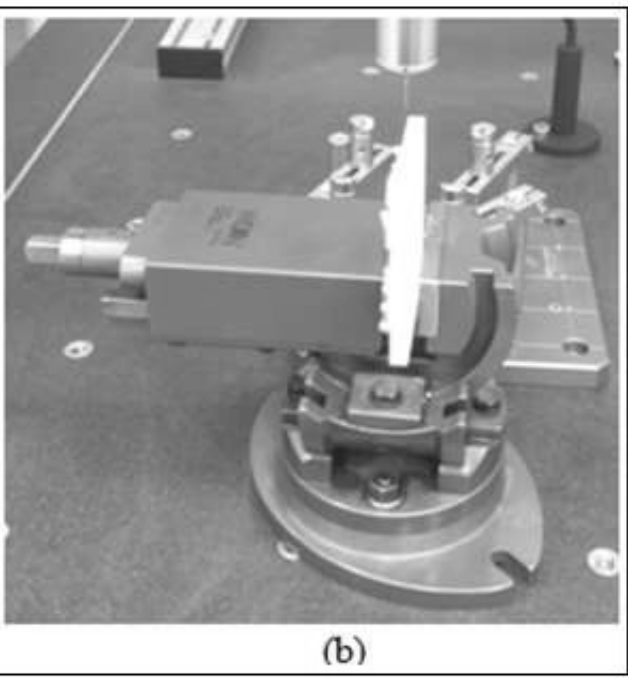

(b)

Figure 6. CMM measurement. (a) Top surface features. (b) Lateral features. 
To accomplish measurements, the part was positioned on the CMM table as demonstrated in Fig. 6 (a) and (b) for the top and lateral features, respectively. This fixture was designed to ensure the same positioning and orientation of the part, reducing human intervention to the minimum. Note that the measurement uncertainty associated with the given CMM machine was $2 \mu \mathrm{m}$. A microscopic examination was conducted for the inspection of fine features, while the surface roughness assessment was achieved through the Talysurf instrument by Taylor Hobson as displayed in Figure 7. The surface roughness was inspected at four locations distributed over the top surface in the four directions. The lateral surfaces were also tested to establish their surface quality.

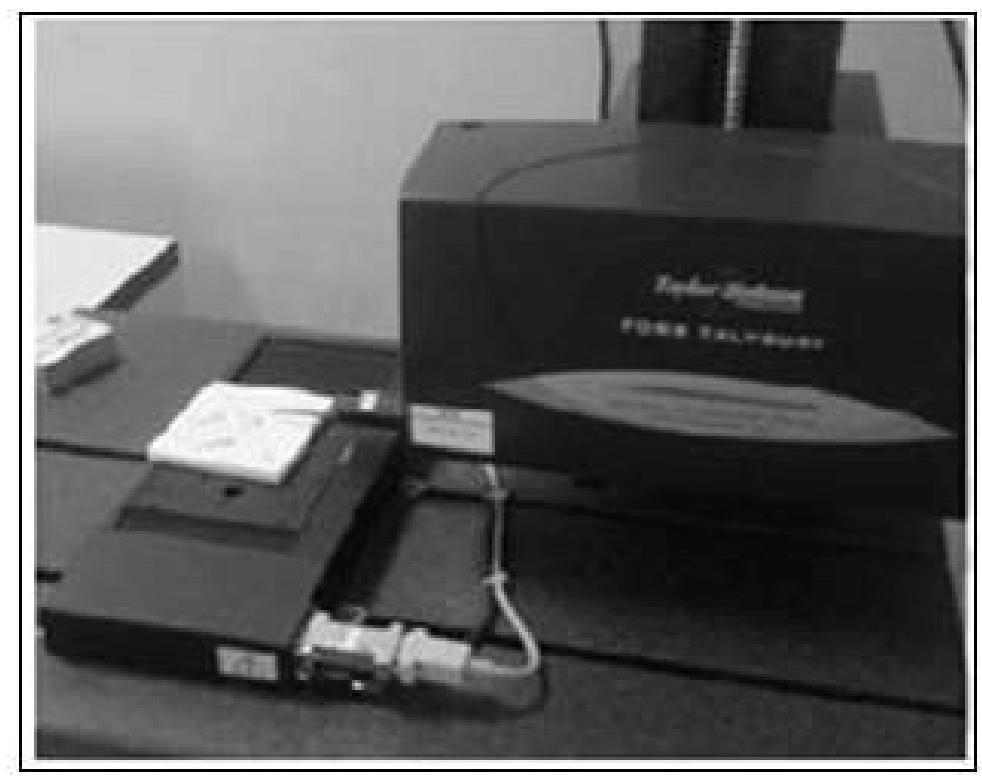

Figure 7. Surface measurement using the Talysurf.

\section{RESULTS AND DISCUSSION}

The statistical values used to quantify the measurement results of this study were the average error, relative error (RE), and the standard deviation (SD) (Dimitrov et al., 2006). The average error can be explained as the variation between the measured quantities of the fabricated parts and the corresponding nominal values (or the design values). It can be concluded here that the average error is a measure of the accuracy and the bias in the measurement results (Galeta et al., 2008). Moreover, the negative error means that the measured value (or the actual value) is lower than the nominal values, or vice versa in the case of the positive error. The RE, on the other hand, represents the error based on the size of the feature being measured and is recorded in percentage. It is very useful when two different features of varying dimensions are needed to be compared. The SD can be defined as the criterion of precision in the measured data. It is a useful indicator when the repeatability of any process needs to be stated. It is indeed a measure of the spread or variation in the data set. The SD is also useful to approximately compute the range of data set through the range rule (Ramirez et al., 2012; Wan et al., 2014). It should also be noted that the following measurement results also included uncertainties (quantified by SD or error bars) due to the operator skills, fixture setup, measurement process, environmental factors, etc. However, these uncertainties have been minimized through the repeated measurements and through ensuring the most appropriate setup.

\section{DEFORMATION OF PART}

The flatness error of $0.1874 \mathrm{~mm}$ and $0.4385 \mathrm{~mm}$ at the top and the bottom surfaces, respectively (Figure 8), as well as the reduction in the length by $0.0183 \mathrm{~mm}$, quantified the deformation in the fabricated part. The primary reason for the deformation according to Moylan et al. (2014) could be the residual stresses introduced by the FDM process. 
The other possible reason for the buckling of the part might be the fatigue in the base plate, as well as the alternating heating and cooling cycles, which led to the thermal gradients and hence the stresses in the part.

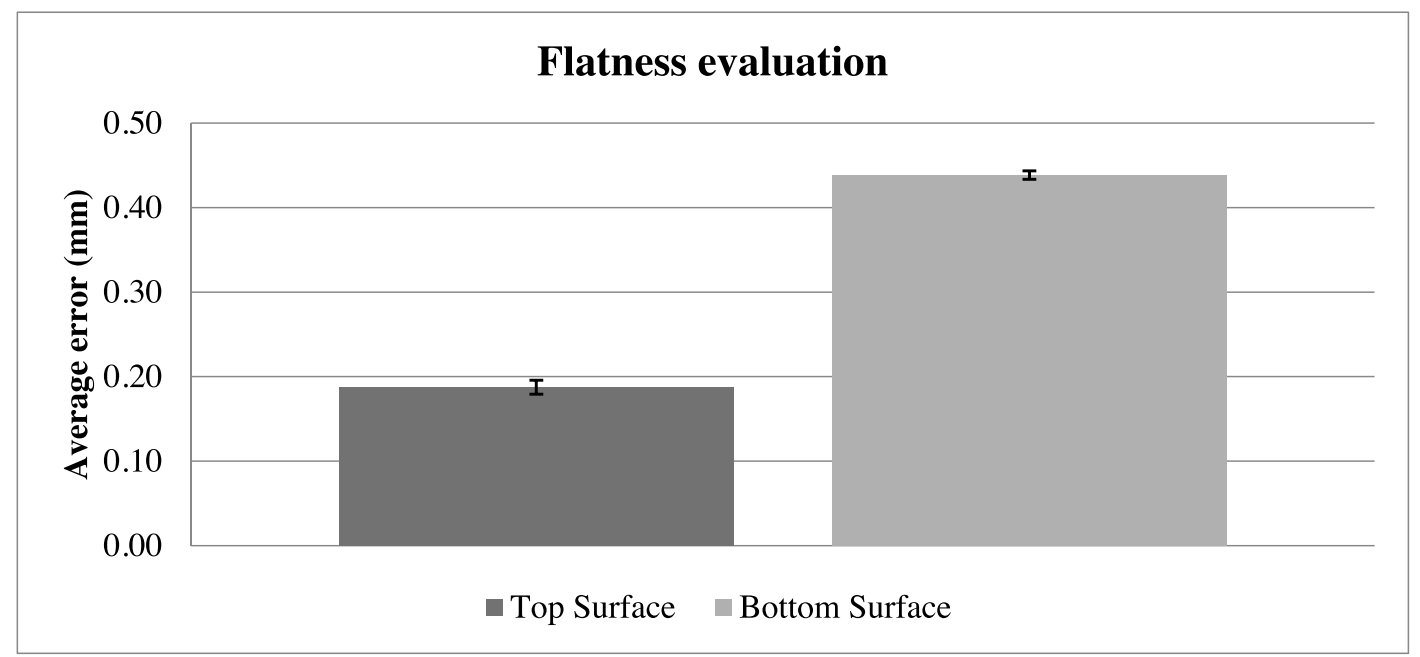

Figure 8. Flatness error in the top and bottom faces of the FDM part.

The average error of $0.0686 \mathrm{~mm}, 0.0892 \mathrm{~mm}$, and $0.0953 \mathrm{~mm}$ for the roundness in the central hole, the inner cylinder, and the outer cylinder, respectively (Table 1), identified the machine's proficiency to realize round features. These findings confirmed that the roundness within $0.0953 \mathrm{~mm}(95.3 \mu \mathrm{m})$ was achieved using this FDM machine.

Table 1. Manufacturing accuracy of center hole, central cylinders, and outer edges.

\begin{tabular}{|c|c|c|c|c|c|c|c|c|c|c|}
\hline Features & \multicolumn{2}{|c|}{ Center hole } & \multicolumn{4}{|c|}{ Central Cylinders } & \multicolumn{4}{|c|}{ Outer edges } \\
\hline $\begin{array}{l}\text { Tolerance } \\
\text { (mm) }\end{array}$ & Roundness & $\begin{array}{l}\text { Perpendicularity } \\
\text { with top surface }\end{array}$ & $\begin{array}{c}\text { Roundness } \\
\text { of inner } \\
\text { cylinder }\end{array}$ & $\begin{array}{c}\text { Roundness } \\
\text { of outer } \\
\text { cylinder }\end{array}$ & $\begin{array}{l}\text { Concentricity } \\
\text { of inner } \\
\text { cylinder to } \\
\text { central hole }\end{array}$ & $\begin{array}{l}\text { Concentricity } \\
\text { of outer } \\
\text { cylinder to } \\
\text { central hole }\end{array}$ & Straightness & Parallelism & Perpendicularity & Length \\
\hline Nominal & 0.0000 & 0.0000 & 0.0000 & 0.0000 & 0.0000 & 0.0000 & 0.0000 & 0.0000 & 0.0000 & 100 \\
\hline Actual & 0.0686 & 0.2337 & 0.0892 & 0.0953 & 0.1303 & 0.1429 & 0.0733 & 0.3399 & 0.2391 & 99.9817 \\
\hline SD & 0.0035 & 0.0046 & 0.0058 & 0.0031 & 0.0072 & 0.0018 & 0.0035 & 0.0039 & 0.0074 & 0.0023 \\
\hline
\end{tabular}

From the concentricity information, it was found that the centers of inner and outer cylinders were approximately $0.1303 \mathrm{~mm}$ and $0.1429 \mathrm{~mm}$ apart, respectively, from the center hole. The higher the accuracy and the straightness of the $\mathrm{z}$-axis motion, the smaller the center distance between the concentric features. It is important here to highlight the fact that, in the case of this FDM machine, the z-axis motion was accomplished through the upward and downward movement of the building platform (or the table). It was also found that the error in the straightness of the outer edges did not exceed $0.0733 \mathrm{~mm}$. The measurement process provided greater consistency, and quality as represented by the lower SD (Table 1).

\section{ACCURACY AND REPEATABILITY ALONG X-AND Y-DIRECTIONS}

To determine the process accuracy and the precision in the $\mathrm{x}$ - and $\mathrm{y}$-directions, the pins and holes were fabricated along their respective axis. It has been observed that the diameter of the pins was larger (positive average error) than their nominal values, while the diameter of the holes was smaller (negative average error) than their corresponding 
nominal values as shown in Figure 9. This might be due to the mismatch between the generated tool path and the extrusion speed. Furthermore, the increased mean diameter of the pins and the reduced average diameter of the holes also pointed to the possible expansion of the different regions on the part. This expansion could be due to the absorption of water from the environment or the solution used during the posttreatment of the fabricated parts. A higher average error for both the pins and the holes along the $\mathrm{y}$-direction, as compared to the $\mathrm{x}$-direction, implied a better manufacturing accuracy for the FDM machine along the $\mathrm{x}$-axis.

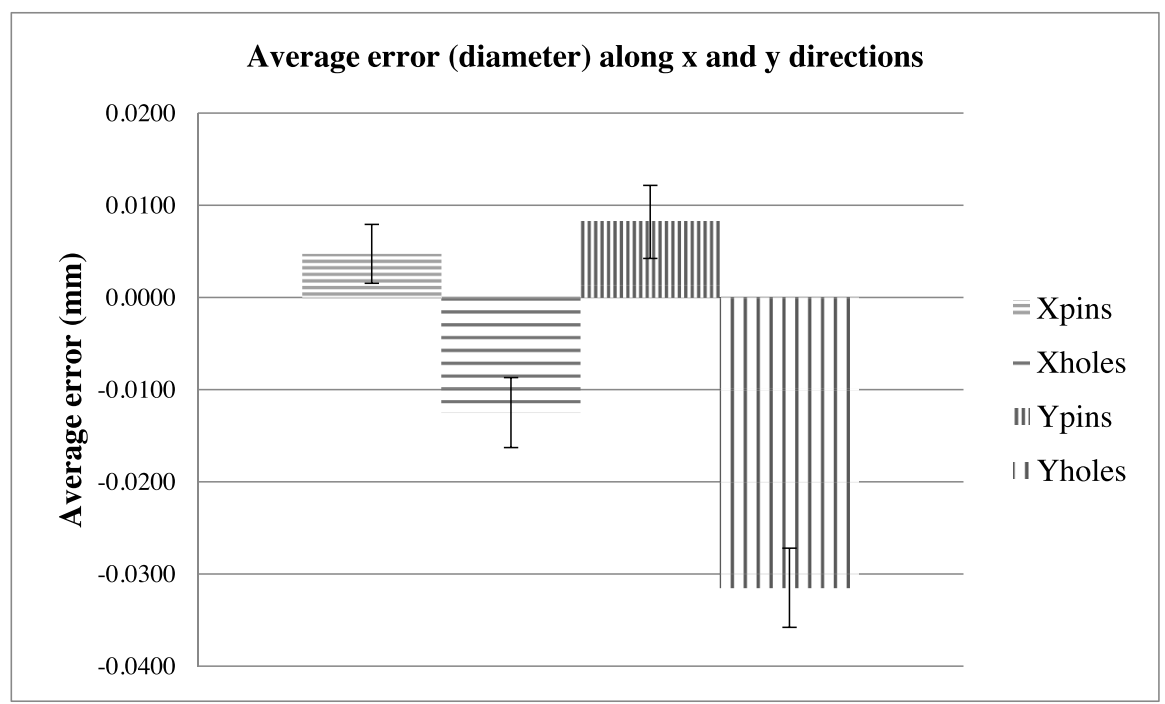

Figure 9. Error in the diameter of pins and holes along the $x$ - and $y$-directions.

The lower RE (in the case of pins) as shown in Figure 10 indicates a higher precision of the machine for the fabrication of pins as compared to the holes. However, the repeatability was roughly the same both along the $\mathrm{x}$ and $\mathrm{y}$ axes as far as the diameter of the pins was concerned.

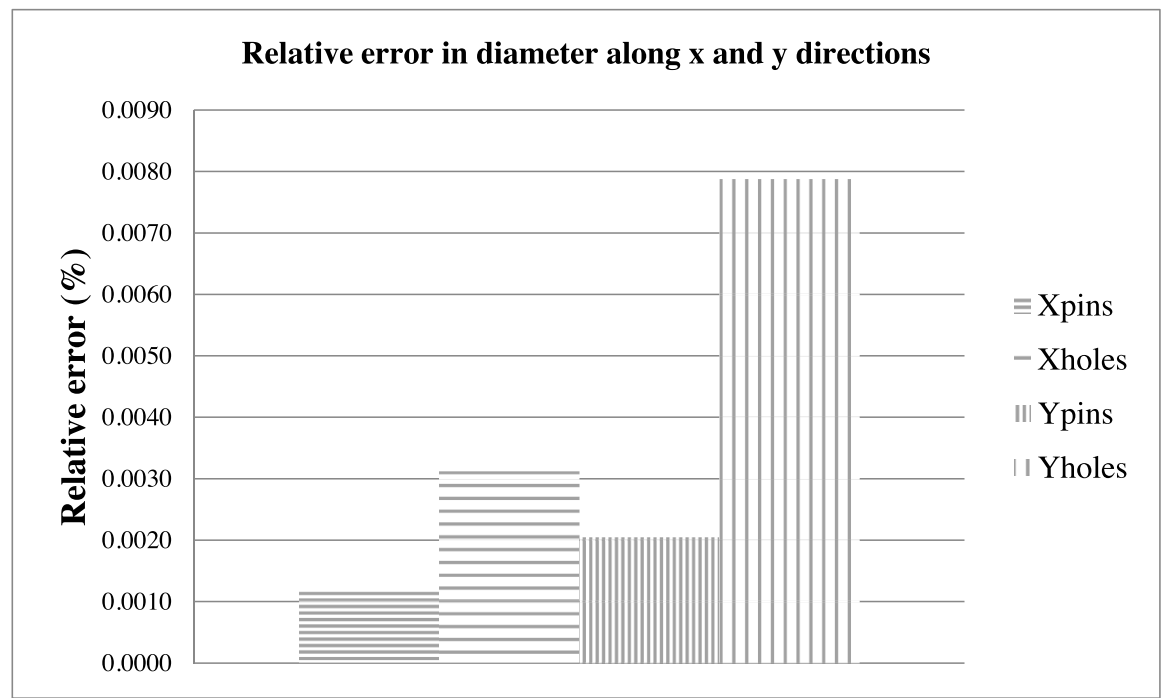

Figure 10. Relative error of pins and holes along the $\mathrm{x}$ and $\mathrm{y}$ axes. 
A higher value of the average error along the y-direction as compared to the x-direction (shown in Fig. 11 (a) and (b)) indicates a poor accuracy of $\mathrm{x}$ - and y-coordinates along the y-direction. Moreover, a negative average error suggests that the nozzle head was producing lower values for both the $\mathrm{x}$ - and $\mathrm{y}$-coordinates when moving along the $\mathrm{x}$ - and y-directions. However, in terms of consistency, the measurements along the $\mathrm{x}$-direction provided better results as compared to the $y$-direction. It can also be pointed out here that the average errors in the $\mathrm{x}$-coordinates were less than those in the $\mathrm{y}$-coordinates along the $\mathrm{x}$ - and the $\mathrm{y}$-directions. According to Moylan et al. (2014), the errors in the pin and hole locations hinted at the geometric errors of the linear axes in the machine.

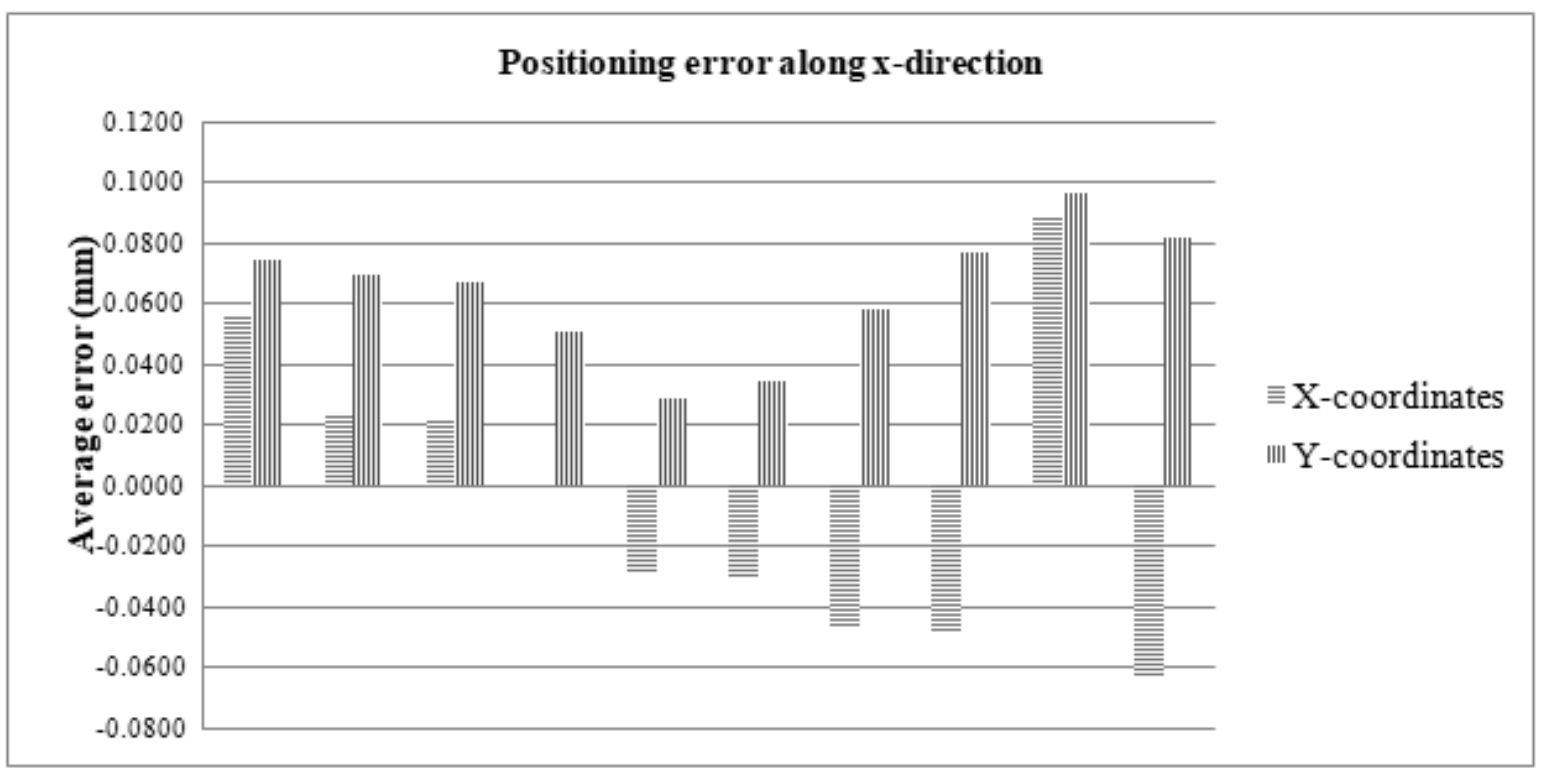

(a)

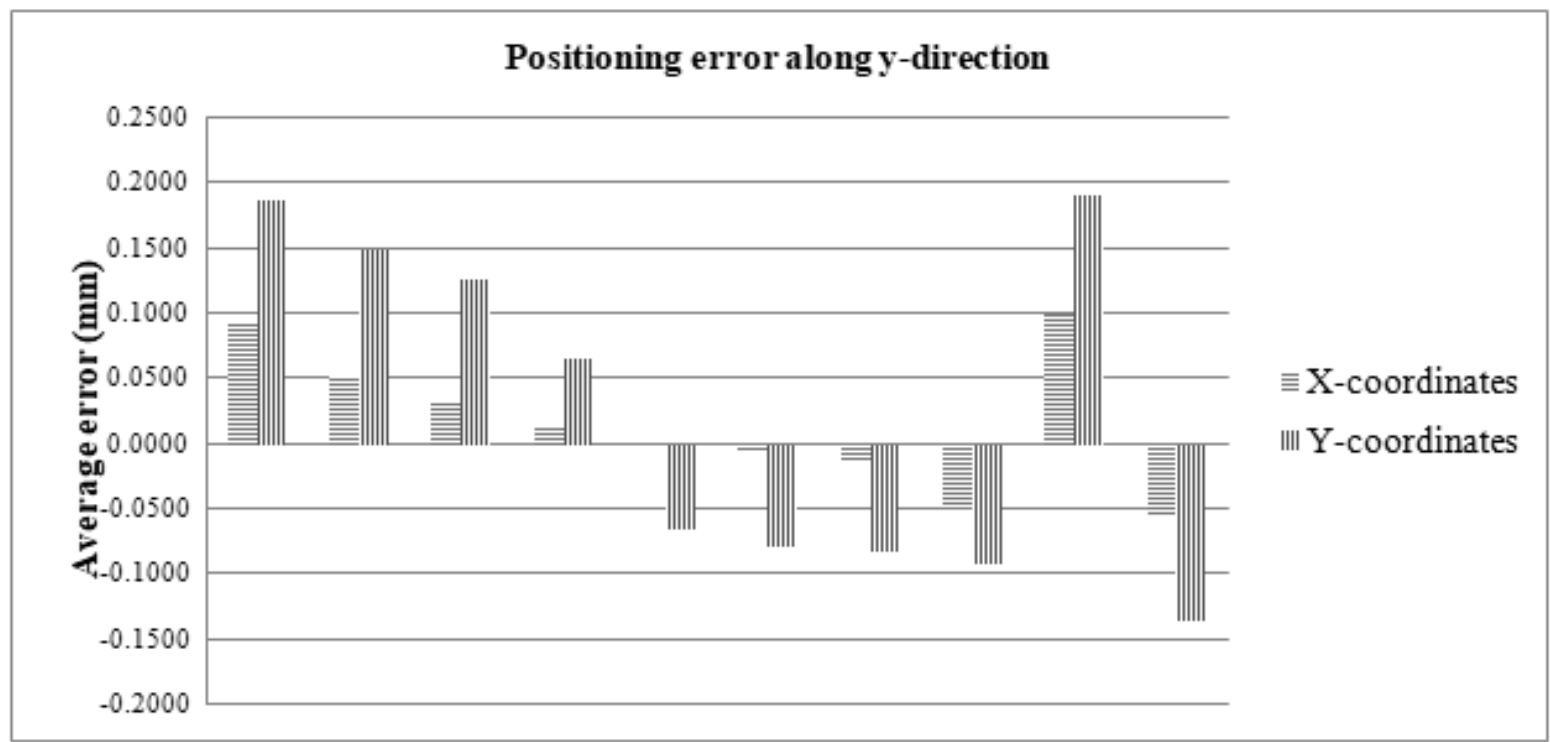

(b)

Figure 11. Positioning error. (a) Along the $\mathrm{x}$-direction. (b) In the $\mathrm{y}$-direction. 


\section{ACCURACY ALONG Z-AXIS}

A significant amount of the average error can be observed in the z-positions for both the positive and the negative staircases as shown in Fig. 12 (a) and (b), respectively. This outcome led to the inference that there existed an inconsistent movement of the building bed along the z-axis in both the positive and negative directions. The errors in the z-positions are generally caused because of the presence of linear displacement error in the machine's z-axis. In the present case, it could be the inaccurate movement of the building platform that caused the error in the z-positions. Moreover, it has been mentioned that the layer thickness is indeed among the most impacting drivers for the z-positions in these cases (Moylan et al., 2014). It can also be reported that the top surfaces in both the positive and negative staircases were below their nominal positions (Fig. 12 (c)).

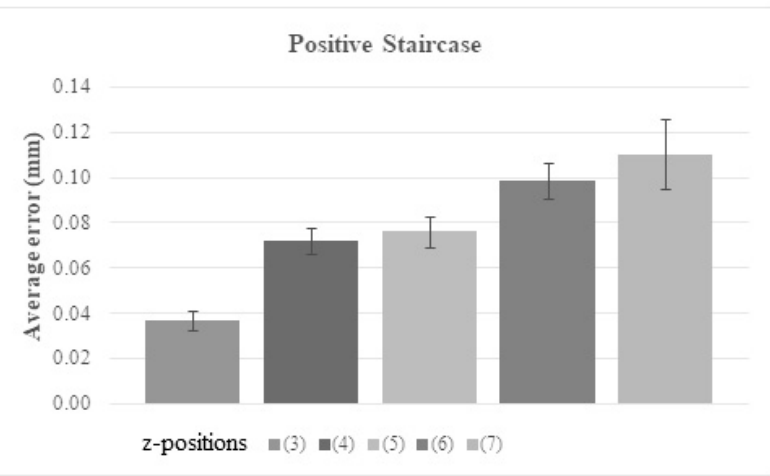

(a)

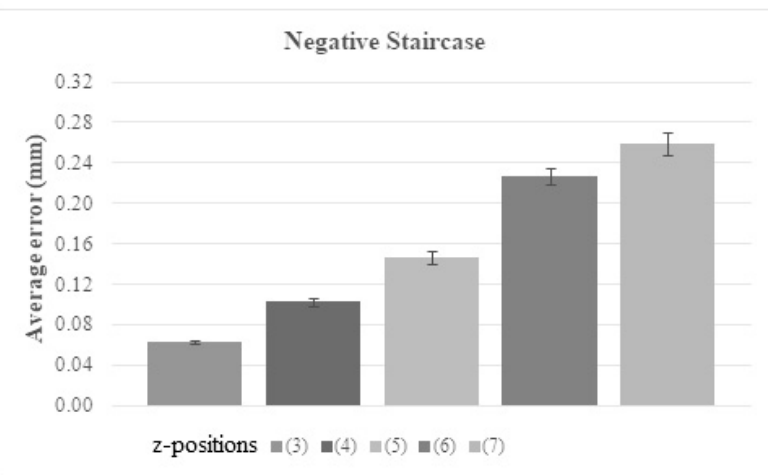

(b)

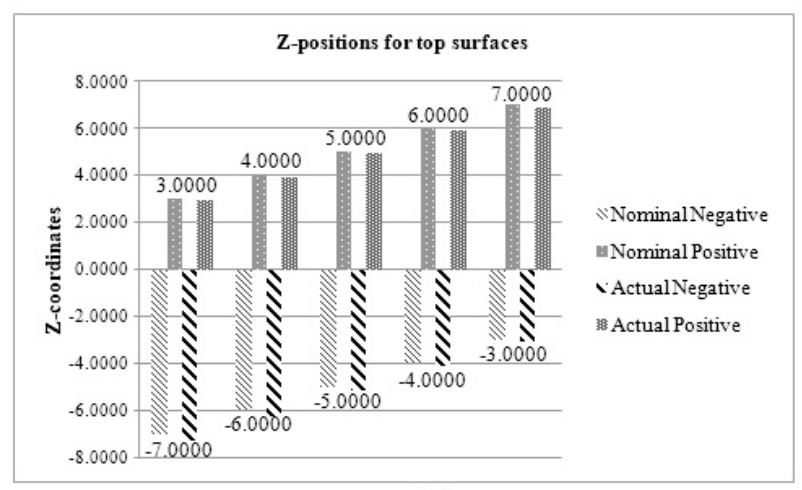

(c)

Figure 12. Average error. (a) Positive staircase. (b) Negative staircase. (c) Z-positions of the top surfaces.

As shown in Fig. 13 (a), the straightness error of the vertical surfaces was high along the y-direction, as compared to the $\mathrm{x}$-direction, for both the positive and the negative staircases. It can also be observed that the vertical surfaces were straight in the positive staircase, as compared to the negative staircase. Moreover, the perpendicularity error seems to be higher in the negative staircase, as compared to the positive staircase (Fig. 13 (b)). Similarly, the parallelism errors in the x-surfaces were lower as compared to the y-surfaces for both the positive and negative staircases. 


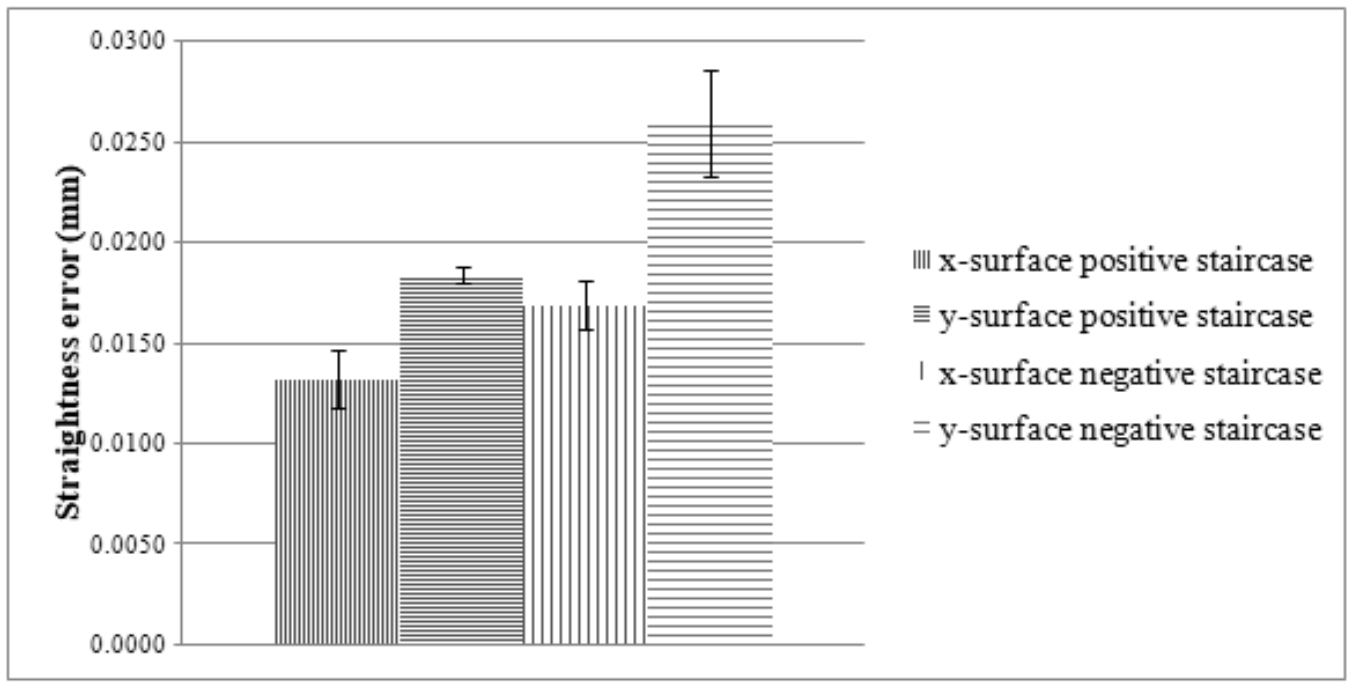

(a)

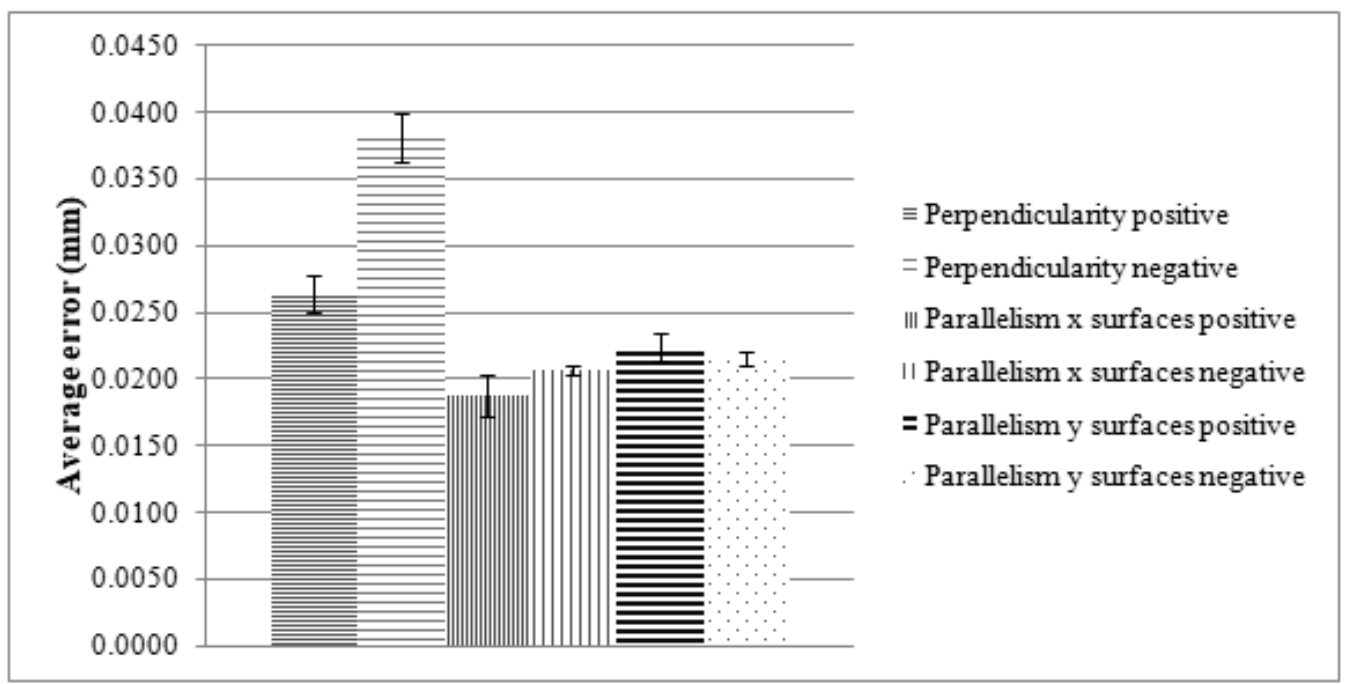

(b)

Figure 13. Positive and negative staircases. (a) Straightness error. (b) Perpendicularity and parallelism errors.

\section{LATERAL FEATURES}

The visual inspection of the fabricated lateral features (Fig. 14 (a) and (b)) confirmed the machine's capability of producing any shape on the vertical plane. The quality of the lateral diamond-shaped features along with the stair-stepping ramp determined the machine's ability to produce a threaded hole. Since this machine was able to manufacture both these features successfully, it can be utilized to fabricate the threaded holes, as well as the 3D contour, on the part. 


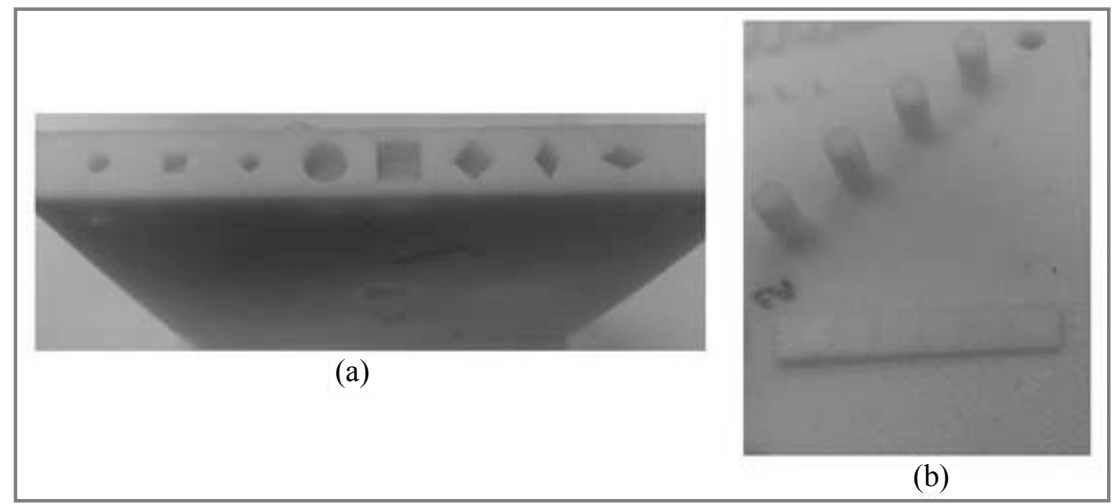

Figure 14. (a) Lateral features. (b) Ramp.

A higher RE was observed for the lateral features when compared with the features on the top surface. For example, the comparison of the hole diameters as shown in Fig. 15 (b) implied a low accuracy in the case of lateral features as compared to the top surface features. Furthermore, a lower average error can be observed in the lateral features with larger dimensions as compared to the features with smaller sizes (Fig. 15 (a)). It can be stated here that the dimensional accuracy of the fabricated features of the vertical face was less as compared to the features on the horizontal face.

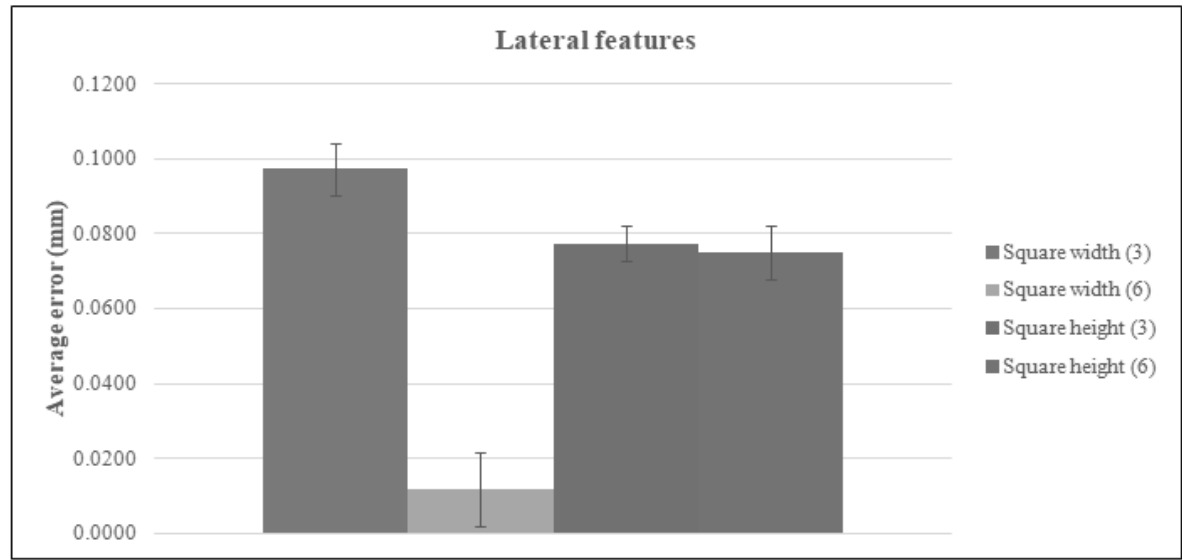

(a)

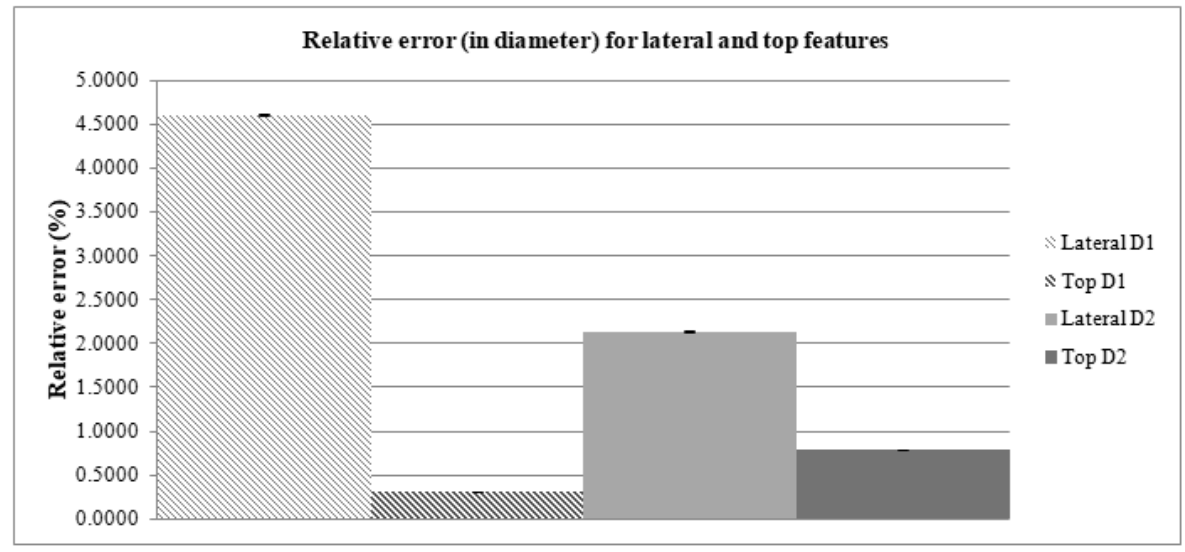

(b)

Figure 15. (a) Average error in the lateral features. (b) Comparison of lateral and top surface features. 


\section{INVESTIGATION OF MICROSCOPIC FEATURES}

When looking at the fine features using the microscope (Table 2), the following conclusions can be drawn:

- Positive features as small as $0.5 \mathrm{~mm}$ could be fabricated successfully.

- Negative features smaller than $1 \mathrm{~mm}$ were not observed.

- Pins with dimensions of 2 and $1.5 \mathrm{~mm}$ were accurately manufactured.

- Holes with dimensions up to $1 \mathrm{~mm}$ were successfully fabricated.

Fine features whether prismatic, circular, positive, or negative with dimensions 0.5 or $0.25 \mathrm{~mm}$ were successfully observed. Nevertheless, they lacked consistency in terms of the cylindricity, roundness, etc. (circular features) and the straightness, perpendicularity, parallelism, etc. (prismatic features).

Table 2. Microscopic investigation of fine features.

\begin{tabular}{|c|c|c|c|c|c|}
\hline Fine Features (mm) & 2 & 1.5 & 1 & 0.5 & 0.25 \\
\hline Positive Features & Yes & Yes & Yes & Yes & No \\
\hline Negative Features & Yes & Yes & Yes & No & No \\
\hline Pins & Yes & Yes & No & No & No \\
\hline Holes & Yes & Yes & Yes & No & No \\
\hline
\end{tabular}

\section{SURFACE ROUGHNESS}

A higher surface finish was observed on the top surface as compared to the side surfaces. The average surface roughness $(\mathrm{Ra})$ observed from the top surface, the side surface, and the ramp was $5.25 \mu \mathrm{m}, 11.37 \mu \mathrm{m}$, and $12.16 \mu \mathrm{m}$, respectively.

\section{CONCLUSION}

The FDM process has tremendous promise in numerous industries because of its abundant benefits, like versatility, the capability to actualize complicated structures, convenience, cost-effectiveness, etc. However, it has been constantly experiencing issues pertaining to poor dimensional and geometrical accuracy of the fabricated parts. Therefore, users need to have substantial information regarding machine capability in terms of achievable accuracy. This paper has illustrated and successfully deployed a simple and effective approach for evaluating the performance of the FDM. This methodology, which was based on the investigation of the standard part, resulted in the following inferences:

- Flatness was affected by the residual stresses that caused buckling in the part.

- Inconsistencies in the platform motion created eccentricity and roundness errors in the cylindrical features.

- The average diameter of the pins was greater than the nominal, while the average diameter of the holes was smaller than their corresponding nominal. This was mainly due to the mismatch between the generated tool path and the extrusion speed.

- Geometric errors of the respective linear axes of $\mathrm{X}$ and $\mathrm{Y}$ caused inaccurate pins and hole locations.

- Lateral features were less accurate as compared to the top surface features. It means that the manufacturing accuracy was better when the features were fabricated on the horizontal face as compared to the vertical face.

- The better surface finish was observed on the top surface as compared to the side surface because of the staircase effect.

- The measurement process provided greater consistency and quality that corroborated the outcome of this investigation. 
Benchmark geometry and a suitable methodology are crucial in improving the technical capabilities of the FDM process. Although this research is specific to a particular machine, it would provide useful information regarding the methodology and strategy that can be employed to retrieve the vital accuracy information on any of the AM technologies.

\section{ACKNOWLEDGMENT}

This work was supported by Researchers Supporting Project Number (RSP-2020/62), King Saud University, Riyadh, Saudi Arabia.

\section{REFERENCES}

Abu Bakar, N.S., Alkahari, M.R. \& Boejang, H. 2010. Analysis of fused deposition modelling performance. Journal of Zhejiang University-SCIENCE A (Applied Physics \& Engineering) 11: 972-977. doi: 10.1631/jzus.A1001365

Ahn D., Kweon J.H., Kwon S., Song J. \& Lee S. 2009. Representation of surface roughness in fused deposition modeling. Journal of Materials Processing Technology, 209: 5593-5600. doi: http://dx.doi.org/10.1016/j.jmatprotec.2009.05.016

Castillo, L. 2005. Study about the rapid manufacturing of complex parts of stainless steel and titanium. TNO report with the collaboration of AIMME, 1-31

Ciurana, J., Sereno, L. \& Valles, E. 2013. Selecting process parameters in RepRap additive manufacturing system for PLA scaffolds manufacture. Procedia CIRP 5: 152-157. doi: 10.1016/j.procir.2013.01.031

Dimitrov, D., Van Wijck, W., Schreve, K. \& De Beer, N. 2006. Investigating the achievable accuracy of three dimensional printing. Rapid Prototyping Journal, 12: 42-52. doi: http://dx.doi.org/10.1108/13552540610637264

Fahad, M. \& Hopkinson, N. 2012. A new benchmarking part for evaluating the accuracy and repeatability of Additive Manufacturing (AM) processes. 2nd International Conference on Mechanical, Production and Automobile Engineering (ICMPAE’2012), Singapore, pp. 234-238

Galeta, T., Kljajin, M. \& Karakašić, M. 2008. Geometric Accuracy by 2-D Printing Model. Strojniški vestnik - Journal of Mechanical Engineering, 54: 725-733

Kochan, D., Kai, C.C. \& Zhaohui, D. 1999. Rapid prototyping issues in the 21 st century. Computers in Industry, 39: 3-10. doi: 10.1016/S0166-3615(98)00125-0

Kruth, J.P., Vandenbroucke, B., Van Vaerenbergh, J. \& Mercelis, P. 2005. Benchmarking of different SLS/SLM processes as rapid manufacturing techniques. Int. Conf. Polymers \& Moulds Innovations (PMI), Gent, Belgium, 20-23

Lee, C.W., Chua, C.K., Cheah, C.M., Tan, L.H. \& Feng C. 2004. Rapid investment casting: direct and indirect approaches via fused deposition modelling. International Journal of Advanced Manufacturing Technology, 23: 93-101. doi: 10.1007/s00170003-1694-y

Mahesh, M., Wong, Y.S., Fuh, Y.H. \& Loh, H.T. 2004. Benchmarking for comparative evaluation of RP systems and processes. Rapid Prototyping Journal, 10: 123-135. doi: http://dx.doi.org/10.1108/13552540410526999

Moylan, S., Slotwinski, J., Cooke, A., Jurrens, K. \& Donmez MA. 2014. An Additive Manufacturing Test Artifact. Journal of Research of the National Institute of Standards and Technology, 119: 429-459. doi: http://dx.doi.org/10.6028/jres.119.017

Ramirez, A. \& Cox, C. 2012. Improving on the Range Rule of Thumb. Rose-Hulman Undergraduate Mathematics Journal 13 (2): Article 1. https://scholar.rose-hulman.edu/rhumj/vol13/iss2/1

Richter, J. \& Jacobs, P. 1992. Accuracy, in: Rapid Prototyping \& Manufacturing, P. Jacobs. Society of Manufacturing Engineers, 287-315

Scaravetti, D., Dubois, P. \& Duchamp, R. 2008. Qualification of rapid prototyping tools: proposition of a procedure and a test part. The International Journal of Advanced Manufacturing Technology, 38: 683-690. doi: 10.1007/s00170-007-1129-2

Singh, S., Sachdeva, A. \& Sharma, V.S. 2012. Investigation of Dimensional Accuracy/Mechanical Properties of Part Produced by Selective Laser Sintering. International Journal of Applied Science and Engineering, 10: 59-68. ISSN 1727-2394

Sood, A.K., Ohdar, R.K. \& Mahapatra, S.S. 2009. Improving dimensional accuracy of Fused Deposition Modeling processed part using grey Taguchi method. Materials and Design, 30: 4243-4252. doi: 10.1016/j.matdes.2009.04.030

Wan, X., Wang, W., Liu, J. \& Tong, T. 2014. Estimating the sample mean and standard deviation from the sample size, median, range and/or interquartile range. BMC Medical Research Methodology 14, 135. https://doi.org/10.1186/1471-2288-14-135 